10. SouzaG,DolinskyM,MatosA, etal.VitaminAconcentration in human milk and its relationship with liver reserve formation and compliance with the recommended daily intake of vitamin Ain pre-term and term infants in exclusive breastfeeding. Arch Gynecol Obstet 2015;291(2):319-25.

11. KingJC. The risk of maternal nutritional depletion and poor outcomes increases in early or closely spaced pregnancies. J Nutr 2003;133(5 Suppl 2):S1732-6.

12. Stoltzfus RL, Underwood BA. Breast milk vitamin A as an indicator to assess vitamin A status of women and infants. Bull World Health Organ 1995;73(5):703-11.
13. Elmadfa I, Meyer AL. Vitamins for the 1000 days: preparing for life. Int J Vitam Nutr Res 2012;82(5):342-7.

14. Souza G, Saunders C, Dolinsky M, et al. Vitamin A concentration in mature human milk. J Pediatr (Rio J) 2012;88(6):496-502.

15. Oliveira AM, Marinho HA. Determinaçaõ de vitamin Ano leite de măes doadoras do banco de leite humano (BLH) de Manaus/AM: efeito do processamento. Acta Amaz 2010;40(1):59-64.

\title{
Renal manifestations in children with Alagille syndrome
}

\author{
Diana Di Pinto, M.D. ${ }^{a}$ and Marta Adragna, M.D. ${ }^{a}$
}

\begin{abstract}
Introduction. Alagille syndrome (AS) is a cholestatic disease secondary to scarcity of interlobular bile ducts. It is associated with extrahepatic manifestations, and renal involvement is frequent.

Objectives. To describe the prevalence, type and outcome of renal pathology in children with AS.

Patients and Methods. The presence and outcome of renal pathology was retrospectively studied in 21 children who met AS criteria.

Results. Renal pathology was observed in 18 patients $(85.7 \%)$ :

(1) ultrasound variations in 7 patients (6 cases of bilateral renal dysplasia and 1 case of renal agenesis); (2) distal renal tubular acidosis in 2 patients; (3) a drop in glomerular filtration and / or proteinuria in 16 patients. The frequency of a drop in glomerular filtration was similar between patients with and without pathological kidney ultrasound findings.

Conclusions. Our study confirms a high prevalence of renal involvement, which enhances the importance of diagnosis and renal function follow-up in children with AS.

Key words: Alagille syndrome, kidney diseases

http:/ / dx.doi.org/10.5546/ aap.2018.eng.149
\end{abstract}

To cite: Di Pinto D, Adragna M. Renal abnormalities in children with Alagille syndrome. Arch Argent Pediatr 2018;116(2):149-153.

a. Department of Nephrology, Hospital Nacional de Pediatría "Prof. Dr. Juan P. Garrahan",

Autonomous City of Buenos Aires, Argentina.

E-mail address:

Diana Di Pinto, M.D.: dianadipinto@yahoo.com

Funding: None.

Conflict of interest: None.

Received: 7-13-2017

Accepted: 9-14-2017

\section{INTRODUCTION}

Alagille syndrome (AS) is a cholestatic disease secondary to scarcity of interlobular bile ducts, and associated to extrahepatic clinical manifestations. ${ }^{1}$ Its prevalence is estimated as 1 case per 70000 individuals and, in most cases, it is due to JAG1 gene mutations. ${ }^{2}$ Normally, it features five "classical" criteria: (1) intrahepatic cholestasis associated to ductopenia in liver biopsy (95\%); (2) heart malformations, typically, stenosis or hypoplasia of the pulmonary artery (92\%); (3) skeletal involvement, generally, butterfly vertebrae $(70 \%)$; (4) eye anomalies, often posterior embryotoxon (78\%); and (5) distinctive facial features $(91 \%)$, as wide forehead, ocular hypertelorism with sunken eyes, prominent ears, triangular face and straight nose. ${ }^{3-5}$ Three out of these five criteria are required for the diagnosis, or two if there is a family history. ${ }^{1}$

Renal involvement is variable (19-74\%), while renal dysplasia is the predominant manifestation (with or without cysts)..$^{1,5-7}$ Besides, distal renal tubular acidosis (dRTA), kidney cysts, urinary tract obstruction, renal agenesis, tubulointerstitial nephritis and vesicoureteral reflux can be observed. 2,4,7 Glomerular changes, like mesangiolipidosis and focal and segmental glomerulosclerosis have also been described, ${ }^{2,8}$ as well as arterial hypertension secondary to renal artery stenosis and other vascular involvements, like middle aortic syndrome, intra-abdominal vascular anomalies and central nervous system abnormalities ${ }^{3}$. Stroke was reported in up to $15 \%$ of cases. ${ }^{3}$

The purpose of this retrospective study was to describe the prevalence, type and outcome of renal 
pathology in children with AS who received care at Hospital de Pediatría "Prof. Dr. Juan P. Garrahan".

\section{PATIENTS AND METHODS}

The medical records of all the children treated in our institution between 1994 and 2016 who met the clinical criteria for AS were revised, and those who lacked a renal assessment either by ultrasound or by specific laboratory tests (estimated glomerular filtration [eGF], acid-base status, ionogram and proteinuria) were excluded. The study was approved by the Ethics and Research Committee.

\section{Operational definitions:}

- A renal ultrasound was regarded as normal if it showed normal shape, size and echotexture for both kidneys, without urinary pathologies, while kidneys were regarded as dysplastic when reduced in size and hyperechogenic, with or without cortical renal cysts. ${ }^{7,9}$

- dRTA: serum bicarbonate $<18 \mathrm{mEq} / \mathrm{L}$ with hyperchloremia and inability to acidify the urine due to an impairment in acid excretion. ${ }^{10}$

- Normal renal function: eGF between 90 and $120 \mathrm{~mL} / \mathrm{min} / 1.73 \mathrm{~m}^{2}$, calculated according to the Schwartz formula. ${ }^{11}$

- Chronic kidney disease (CKD): proteinuria (>5 mg/ kg/day or proteinuria/creatininuria index $>2$ ) over more than 3 months, abnormal urinary sediment, tubular disorders, abnormalities detected through images or histology, and / or history of kidney transplant. ${ }^{12}$

- Arterial hypertension: systolic and/or diastolic blood pressure $>$ 95th percentile, according to the "Fourth Task Force Report". ${ }^{13}$

\section{Statistical analysis}

Clinical and demographic characteristics and ultrasound findings were analyzed descriptively. Continuous outcome measures had a normal distribution (Shapiro-Wilk's test), so they were expressed as a median (range), while categorical outcome measures were reported as an occurrence rate and percentage. Categorical outcome measures comparison was performed using Fisher's exact test (significance level was $p$ $<0.05)$. Statistix 7 software was used.

\section{RESULTS}

A total of 25 patients who met the AS clinical criteria were identified; 4 of these patients were excluded because they lacked a kidney ultrasound. Therefore, the sample size was of 21 children (16 males). Mean age was 12.3 years (2.6-19.2) and age at the time of AS diagnosis was 0.5 years $(0.08-8.4)$. Table 1 shows the frequency of different organs involvement; the prevalence of renal pathology was $85.7 \%$ (18 patients). It was characterized by the presence of structural alterations in 7 cases (bilateral dysplasia in 6 cases and agenesis in 1 case). Two patients developed dRTA; one of the cases was associated to renal dysplasia.

Patients were followed up for 9.6 years (0.717.4), and 10 of them received a liver transplant. During the course of the disease, 16 patients developed an eGF $<90 \mathrm{ml} / \mathrm{min} / 1.73 \mathrm{~m}^{2}$ and $/$ or proteinuria; in 6 cases, these alterations appeared after the liver transplant. Two patients required renal function replacement therapy: one initiated chronic hemodialysis and the other received a kidney transplant (both had renal dysplasia). The frequency of a drop in the glomerular filtration rate (eGFR) was comparable between patients with and without pathological kidney ultrasound findings ( $5 / 7$ vs. $5 / 14$, respectively; $p=0.18$ ). No patients developed arterial hypertension. Table 2 describes the findings and the renal outcome for each of the study patients.

TABLE 1. Different organs involvement in series of children with Alagille syndrome

\begin{tabular}{lccccc}
\hline Finding & $\begin{array}{c}\text { Current study } \\
(\mathbf{n}=\mathbf{2 1})\end{array}$ & $\begin{array}{c}\text { Quiros-Tejeira } \\
(\mathbf{n}=43)\end{array}$ & $\begin{array}{c}\text { Alagille } \\
(\mathbf{n}=\mathbf{8 0})\end{array}$ & $\begin{array}{c}\text { Hoffenberg } \\
(\mathbf{n}=\mathbf{2 6})\end{array}$ & $\begin{array}{c}\text { Kamath } \\
(\mathbf{n}=\mathbf{1 8 7})\end{array}$ \\
\hline Renal involvement & $85.7 \%(18 / 21)$ & $50 \%(15 / 30)$ & $73.9 \%(17 / 23)$ & $19 \%(5 / 26)$ & $39 \%(73 / 187)$ \\
Intrahepatic cholestasis & $100 \%(21 / 21)$ & $100 \%(43 / 43)$ & $91 \%(73 / 80)$ & $100 \%(26 / 26)$ & ND \\
Abnormal facies & $95.2 \%(20 / 21)$ & $98 \%(42 / 43)$ & $95 \%(76 / 80)$ & $92 \%(23 / 25)$ & ND \\
Heart malformations & $85.7 \%(18 / 21)$ & $98 \%(42 / 43)$ & $85 \%(68 / 80)$ & $96 \%(24 / 25)$ & ND \\
Skeletal involvement & $57.1 \%(12 / 21)$ & $38 \%(12 / 32)$ & $87 \%(70 / 80)$ & $48 \%(11 / 23)$ & ND \\
Eye anomalies & $38.1 \%(8 / 21)$ & $73 \%(16 / 22)$ & $88 \%(55 / 62)$ & $85 \%(17 / 20)$ & ND \\
\hline
\end{tabular}

ND: No data. 


\section{DISCUSSION}

In patients with AS, the frequency of renal involvement ranges between $19 \%$ and $74 \% .{ }^{1,5-7} \mathrm{In}$ our series, it was detected in $85.7 \%$ (18 patients) of the patients, and there was a drop of the eGF and/or proteinuria in 16 patients during followup. In Kamath's study, the largest study including adults as well as children, the prevalence was $39 \%,{ }^{7}$ while in series with a smaller number of patients, it was highly variable (Table 2) . $^{1,5-7}$

The prevalence of renal injury in our series was high, probably due to our hospital being a tertiary care center and to the inclusion of patients who received a liver transplant.

The most frequent renal structural anomaly was renal dysplasia (28.5\%), also prevalent in the Kamath et al. series (58.9\%). ${ }^{7}$ dRTA prevalence, observed in two of our patients $(9.5 \%)$, was similar to the one reported in other series $(7-9 \%) .{ }^{6,7}$

No other manifestations, like renal cystic lesions $(10 \%)$ and urinary tract obstruction $(8.2 \%$ $10 \%$ ), were observed among our patients. ${ }^{1,7}$
eGF drop is frequent in the presence of known renal involvement. ${ }^{7}$ In Kamath's series, 38\% of the patients with renal structural anomalies showed a drop in GF, and renal dysplasia (1/3 patients) was the most frequent finding. ${ }^{7}$ In our study, 10 children $(47.6 \%)$ developed an eGF drop at the end of the follow up period and, as in the above mentioned study, in these cases, bilateral renal dysplasia was also a prevalent structural finding (4 patients). It is also worth mentioning that drops in eGF and/or proteinuria were observed in patients without ultrasounddetectable renal alterations. Mesangiolipidosis is a particular histopathological pattern of glomerular lesions characterized by the presence of foam cells and / or lipid vacuoles in the mesangium. ${ }^{4}$ Habib et al. observed this in 18/26 patients' biopsies (70\%); 12 of them showed a drop of the eGF and 3 of them showed non-nephrotic range proteinuria. ${ }^{4}$ Very rarely, focal and segmental glomerulosclerosis can be observed, though this has only been described in 2 adult patients. ${ }^{2,8}$

TABLE 2. Renal involvement in 21 children with Alagille syndrome

\begin{tabular}{|c|c|c|c|c|c|}
\hline Patient & $\begin{array}{c}\text { Age at AS diagnosis } \\
\text { (years) }\end{array}$ & $\begin{array}{l}\text { Gender } \\
(\mathrm{F} / \mathrm{M})\end{array}$ & $\begin{array}{l}\text { Kidney } \\
\text { ultrasound }\end{array}$ & Lab tests & $\begin{array}{c}\text { Age at } \\
\text { last follow-up (years) }\end{array}$ \\
\hline 1 & 0.08 & $\mathrm{M}$ & Dysplasia & Proteinuria* Low eGF & 18.3 \\
\hline 2 & 8.4 & $\mathrm{~F}$ & Dysplasia & Proteinuria Low eGF & 19.2 \\
\hline 3 & 0.90 & M & Dysplasia & Proteinuria* Low eGF ${ }^{* *}$ & 17.8 \\
\hline 4 & 5.8 & M & Agenesis & Low eGF & 17.6 \\
\hline 5 & 0.2 & M & Dysplasia & RTA low eGF & 3.2 \\
\hline 6 & 7.3 & M & Dysplasia & Proteinuria & 1.2 \\
\hline 7 & 0.2 & $\mathrm{~F}$ & Dysplasia & Normal & 11.2 \\
\hline 8 & 0.6 & $\mathrm{M}$ & Normal & Proteinuria Low eGF** & 14.5 \\
\hline 9 & 0.4 & $\mathrm{M}$ & Normal & Proteinuria Low eGF & 15.6 \\
\hline 10 & 2.1 & M & Normal & Low eGF & 2.8 \\
\hline 11 & 0.4 & $\mathrm{~F}$ & Normal & Low eGF & 4.7 \\
\hline 12 & 0.2 & M & Normal & Low eGF & 9.2 \\
\hline 13 & 0.99 & $\mathrm{M}$ & Normal & Proteinuria $^{* *}$ & 18.4 \\
\hline 14 & 0.5 & $\mathrm{~F}$ & Normal & Proteinuria** & 13.8 \\
\hline 15 & 0.2 & $\mathrm{M}$ & Normal & Proteinuria** $^{* *}$ & 5.8 \\
\hline 16 & 5.7 & $\mathrm{M}$ & Normal & Proteinuria** $^{* *}$ & 9.6 \\
\hline 17 & 0.3 & $\mathrm{~F}$ & Normal & Proteinuria & 4.4 \\
\hline 18 & 1.6 & $\mathrm{M}$ & Normal & RTA & 6.1 \\
\hline 19 & 0.3 & M & Normal & Normal & 17.6 \\
\hline 20 & 0.2 & $\mathrm{M}$ & Normal & Normal & 2.5 \\
\hline 21 & 3.3 & M & Normal & Normal & 18.1 \\
\hline
\end{tabular}

AS: Alagille syndrome; F/M: female/male; eGF: estimated glomerular filtration; RTA: renal tubular acidosis.

* Required renal function replacement therapy.

** Renal impairment occurred after liver transplant. 
Although none of our patients underwent a renal biopsy, it might be assumed that this group presented such histological lesions, which accounted for their renal function impairment. This highlights the importance of looking for renal compromise in every patient, including those without structural pathologies. Furthermore, it should be kept in mind that $15-20 \%$ of these patients are future transplant receptors, which implies the subsequent exposure to nephrotoxic drugs (calcineurin inhibitors as tacrolimus or cyclosporin, and nephrotoxic antibiotics) and a greater risk of developing CKD, as was the case in 6 out of the 10 patients who received a liver transplant., ${ }^{2,14}$ Finally, 2 patients (both with renal dysplasia) required renal replacement therapy, though this outcome was rare. ${ }^{15}$

The high prevalence of renal involvement observed in our patients strengthens the need of a regular assessment of renal function within this population, which should include kidney ultrasound, serum chemistry, urinalysis and blood pressure measurement. Since all our patients had normal blood pressure values, no vascular tree tests were performed. Yet, vascular pathologies should be ruled out in cases of arterial hypertension. Besides, a renal biopsy should be performed in those patients without renal structural defects and drop of eGF and/ or proteinuria and/or albuminuria, in order to diagnose glomerular lesions.

\section{CONCLUSIONS}

The prevalence of renal involvement was high $(85.7 \%)$ in the AS patients of our series. Renal dysplasia was the most frequent structural alteration; however, renal function impairment was observed in patients with normal kidney ultrasound findings. Sixteen of the 21 study patients developed a drop in eGF and/or proteinuria by the end of follow-up; in 6 of them, these alterations appeared after receiving a liver transplant. These findings highlight the importance of a systematic and regular search of renal pathologies in this population, even in those patients without proof of structural abnormalities.

\section{REFERENCES}

1. Quiros-Tejeira RE, Ament ME, Heyman MB, et al. Variable morbidity in Alagille syndrome: A review of 43 cases. J Pediatr Gastroenterol Nutr 1999;29(4):431-7.

2. Jacquet A, Guiochon-Mantel A, Noël LH, et al. Alagille syndrome in adult patients: It is never too late. Am J Kidney Dis 2007;49(5):705-9.

3. Turnpenny PL, Ellard S. Alagille syndrome: pathogenesis, diagnosis and management. EurJ Hum Genet 2012;20(3):251-7.

4. Habib R, Dommergues JP, Gubler MC, et al. Glomerular mesangiolipidosis in Alagille syndrome. Pediatr Nephrol 1997;1(3):455-64.

5. Alagille D, Estrada A, Hadchouel M, et al. Syndromic paucity of interlobular bile ducts (Alagille síndrome or arteriohepatic displasia): Review of 80 cases. J Pediatr 1987;110(2):195-200.

6. Hoffenberg EJ, Narkewicz MR, Sondheimer JM, et al. Outcome of syndromic paucity of interlobular bile ducts (Alagille syndrome) with onset of cholestasis in infancy. J Pediatr 1995;127(2):220-4.

7. Kamath BM, Podkameni G, Hutchinson AL, et al. Renal anomalies in Alagille syndrome: A disease-defining feature. Am J Med Genet A 2012;158A(1):85-9.

8. Davis J, Griffiths R, Larkin K, et al. Glomerular basement membrane lipidosis in Alagille syndrome. Pediatr Nephrol 2010;25(6):1181-4.

9. Massanyi EZ, Preece J, Gupta A, et al. Utility of screening ultrasound after first febrile UTI among patients with clinically significant vesicoureteral reflux. Urology 2013;82(4):905-9.

10. Masso D, Repetto H. Fisiología y fisiopatología de la homeostasis del estado ácido base. In: Ferraris J, Briones Orfila (edit). Nefrología pediátrica. Buenos Aires: FUNDASAP; 2008.Pages.355-80.

11. Schwartz GJ, Haycock GB, Edelmann CM Jr, et al. A simple estimate of glomerular filtration rate in children derived from body length and plasma creatinine. Pediatrics 1976;58(2):259-63.

12. KDIGO 2012 Clinical Practice Guideline for the Evaluation and Management of Chronic Kidney Disease. Kidney Int. 2013;3(1). [Accessed on: September 27 $\left.{ }^{\text {th }}, 2017\right]$. Available at: http: / / www.kdigo.org/clinical_practice_guidelines / pdf/CKD/KDIGO_2012_CKD_GL.pdf.

13. National High Blood Pressure Education Program Working Group on High Blood Pressure in Children and Adolescents. The fourth report on the diagnosis, evaluation, and treatment of high blood pressure in children and adolescents. Pediatrics 2004;114(2Suppl4th Report):S555-76.

14. Kamath BM, Bauer RC, Loomes KM, et al. NOTCH2 mutations in Alagille syndrome. J Med Genet 2012;49(2): 138-44.

15. Schonck M, Hoorntje S, Van Hooff J. Renal transplantation in Alagille syndrome. Nephrol Dial Transplant 1998;13(1): 197-9. 